\title{
A crise estrutural do capital, as relações Estado-sociedade e o mito do terceiro setor
}

\section{The structural crisis of capital, State-society relations and the myth of the third sector}

\author{
Reginaldo Pereira França Junior ${ }^{a}$ \\ (1) https://orcid.org/0000-0002-6097-6756
}

Resumo: O artigo busca refletir sobre as crises do capital, bem como sobre o processo de consolidação das determinações da acumulaçãoflexível na produção e nas finanças, no mundo do trabalho e nas relações Estado-sociedade. A reestruturação produtiva alterou as relações sociais, minimizou o Estado, possibilitou a conversão das políticas sociais em mercadorias, fortalecendo o terceiro setor como uma das saídas mágicas às crises de produção, muito embora a saída da crise seja a superação dessas relações sociais.

Palavras-chaves: Reestruturação Produtiva. Trabalho. Relações Estado-Şociedade. Terceiro Setor.
Abstract: The article seeks to reflect on the crises of capital, as well as the process of consolidating the determinations of flexible accumulation in production and finance, in the world of work and in Statesociety relations. Productive restructuring altered social relations, minimized the State, made it possible to convert social policies into commodities and strengthened the third sector as one of the magic ways out of production crises, even though the way out of the crisis is to overcome these social relations.

Keywords: Productive Restructuring. Work. State-Society Relations. Third Sector. 


\section{Introdução}

ste artigo busca evidenciar reflexões sobre as crises cíclicas do capital e suas determinações na esfera do mundo do trabalho, bem como suas mais íntimas relações com o Estado e um terceiro setor privado, eufemisticamente chamado de "filantrópico", que tem como função reforçar a submissão das políticas sociais a mercadorias negociáveis, reafirmando a lógica de um Estado mínimo para os trabalhadores e máximo para a extração de mais-valor.

Tomando o método marxista como referência para nossas análises, é preciso compreender que as profundas alterações ocorridas nas relações sociais de produção, na transição dos séculos XX e XXI, colocam em constante evidência a necessidade de produzir análises e reflexões na busca de explicar e possibilitar a construção de referências para entender as reconfigurações no padrão de acumulação capitalista ocorridas em escala global.

Tais mutações afiançam profundas transformações e repercussões na realidade do trabalho nos países de capitalismo avançado, com maior destaque nos países periféricos, e nos impõem a necessidade de compreender o processo de produção capitalista, com ênfase no papel do Estado diante dos despojos do capital frente a sua incontrolável necessidade de uma contínua e exponencial valorização.

A retração do Estado abre generoso espaço de ampliação de uma pretensa "sociedade civil" autonomizada dos demais processos, sustentada pela falaciosa esfera do terceiro setor, que draga recursos públicos, elabora, gerencia e executa as políticas públicas e, com isso, seleciona a inclusão a programas, projetos e serviços de uma considerável parcela de trabalhadores que estão à margem da política social estatal, transformando os direitos em serviços e reforçando seu caráter individualizante.

\section{A agudização das crises de reprodução do capital}

Portador de caráter anti-humano e destrutivo, o capital lança sobre a sociabilidade um profundo processo de reordenamento, recriando, na 
velha e necessária (para o capital) exploração da força de trabalho, novos contornos, cada vez mais agudos, em que a lógica da intensificação do ritmo da produção coaduna com o aprofundamento do recrudescimento dos direitos sociais e humanos. 0 capitalismo contemporâneo restabelece, sob novas e agudas bases, o conflito capital-trabalho, sobretudo, “[...] após um longo período de acumulação de capitais, que ocorreu durante o apogeu do fordismo e da fase keynesiana [...]" (Antunes, 2003. p. 30).

Sustentados pela queda tendencial da taxa de lucro, o esgotamento do padrão de acumulação taylorista/fordista de produção, pela hipertrofia da esfera financeira, da ampliação da concentração de capitais, a crise do Welfare State nos países centrais e o incremento acentuado das privatizações acarretam a reestruturação produtiva em novas bases, na acumulação flexível.

Já demonstrando um profundo esgotamento do modelo de produção assentado na chamada "onda longa expansiva" ${ }^{1}$ do capitalismo, a crise do modelo taylorista-fordista se consolida em razão de não mais atender aos interesses da acumulação do capital,

[...] exacerbada pelo choque do petróleo, que evidentemente retirou o mundo capitalista do sufocado torpor da estagflação (estagnação da produção de bens e alta inflação de preços). Essa exacerbação derivada da crise do petróleo pôs em movimento um conjunto de processos que solaparam o compromisso fordista (Harvey, 2014, p. 140).

Nesse mesmo período, novas formas de organização do trabalho e a incorporação de novas tecnologias pareciam apontar para uma fase de introdução acelerada do trabalho morto em substituição ao trabalho

\footnotetext{
1 Para Mandel (1985, p. 76), as ondas expansivas experimentadas pelo capital "representam realidades históricas, segmentos da história global do modo de produção capitalista que possuem umas quebras claramente distintivas. Por essas mesmas razões são de duração irregular", entendendo que essas ondas expansivas são resultantes de processos que, considerada uma clivagem econômico-ambiental endógeno-exógena, representam a correlação de forças socioeconômicas, profundamente irrigadas pela concorrência intercapitalista.
} 
vivo. O capital busca eliminar sua mais profunda contradição: o conflito capital-trabalho, adotando o modelo japonês de produção, o toyotismo, também chamado de acumulação flexível.

Muito embora necessite do trabalho para a sua realização, ou seja, para a criação de valor e mais-valor, tanto pela via da produção, quanto pela via do consumo, o modelo japonês de gerenciamento da produção não supera os laços de dependência do capital em relação à força de trabalho, residindo uma contradição operante, situando o capital na perspectiva de uma negação de si mesmo (Harvey, 2014).

A relação entre as tendências da crescente substituição do padrão taylorista/fordista e a desregulação estatal clarifica a observação de que “[...] como resposta à queda das taxas de lucro na década de 1970, os anos 1980 são marcados por uma ofensiva revolução tecnológica na produção [...], pela globalização da economia e pelo ajuste neoliberal" (Behring, 2001, p. 128). Nessa década, após a explosão da crise, tem início uma fase em que a engenharia capitalista sofre uma intensa reestruturação, com base na revolução da microeletrônica e pela informática aplicada à informação.

Da produção em série e em massa (taylorismo-fordismo), transfere-se para o processo de acumulação flexível (toyotismo), que apresenta a célula de produção como estratégia para reduzir seus custos diretos e indiretos (principalmente sobre a força de trabalho), além de reduzir as estruturas hierárquicas das fábricas. Também é possível afirmar que os modelos encontram-se convivendo com indústrias já totalmente adaptadas à acumulação flexível, outras com a manutenção do taylorismo-fordismo e muitas com um sistema híbrido de produção.

O esgotamento do padrão de acumulação taylorista/fordista, acompanhado pela intensificação dos profundos avanços tecnológicos, provocou alterações no processo de (re)produção de capital, com sérias repercussões nos processos de trabalho. A "crise" do capitalismo emerge como uma resposta programática do próprio capital, na direção de reposicionar os processos produtivos, evidenciados pelo reordenamento 
macroestrutural da economia, calcada na acentuação da produção e na exponencial minimização das taxas de ocupação de força de trabalho, bem como no aprofundamento da flexibilização.

Para Antunes (2003, p. 31),

[...] como resposta à sua própria crise, iniciou-se um processo de reorganização do capital e de seu sistema ideológico e político de dominação, cujos contornos mais evidentes foram o advento do neoliberalismo, com a privatização do Estado, a desregulamentação dos direitos do trabalho e a desmontagem do setor produtivo estatal, da qual a era Thatcher-Reagan foi expressão mais forte; a isso se seguiu também um intenso processo de reestruturação da produção e do trabalho, com vistas a dotar o capital do instrumental necessário para tentar repor os patamares de expansão anteriores.

As interpretações sobre as crises cíclicas do capital, seus estudos e avaliações de suas implicações não permitem a elaboração de quaisquer tipos de consensos que fujam à validade contida no método em Marx. Dessa polêmica, resultam conclusões contraditórias, muitas delas otimistas que, no presente momento, demonstram, realmente, um otimismo exagerado em razão da crise capitalista global atual que, segundo muitos analistas, é mais profunda e mais vultosa que a crise de 1929, impondo, desde 2008, os reflexos de uma crise estrutural e cíclica, endógena ao sociometabolismo do capital, que seguiu profundamente catalisada e avolumada pela crise das hipotecas subprime (Harvey, 2014). O reflexo dessa crise provocou uma longa onda de depressão e, no Brasil,

[...] logo após o golpe de 2016, com o governo Temer (2016-2018) e, por conseguinte, o governo Bolsonaro, este país tropical tornou-se hoje [...] o paraíso exuberante de bizarrices da modernidade senil. [...] nos tornamos o primeiro vagão do trem do capitalismo neoliberal rumo ao abismo (Alves, 2019, p. 31). 
No cenário atual, a dinâmica da crise capitalista, além de acentuar a taxa de exploração dos trabalhadores (força de trabalho ocupada e/ou desocupada), neste momento, atinge também o capital transnacional e globalizado, deixando um rastro no encolhimento de ativos e, principalmente, atingindo o centro do capitalismo fundado na esfera das finanças, pulverizando o valor de outros ativos financeiros.

A explicação da dinâmica do capitalismo está na sua finalidade essencial que é a expansão constante do valor de troca, desde as mais primárias e mais íntimas necessidades dos indivíduos até as mais variadas atividades de produção, quer sejam espirituais e/ou materiais, a que devem subordinar-se. Assim, é no capitalismo que se registra o aprofundamento da lógica que promove acentuadamente a dicotomia entre a produção voltada para o atendimento das necessidades humanas e a produção voltada para a constante valorização do capital, o que, segundo Antunes (2003, p. 26) evidencia a

[...] separação entre a produção voltada genuinamente para o atendimento das necessidades humanas e as necessidades de auto-reprodução de si próprio. Quanto mais aumentam a competição e a concorrência intercapitais, mais nefastas são suas consequências, das quais duas são particularmente graves: a destruição e/ou precarização, sem paralelos em toda a era moderna, da força humana que trabalha e em si não passa de um modo e um meio dinâmico de mediação reprodutiva, devoradora e dominadora, articulada com um conjunto historicamente específico de estruturas e suas práticas sociais institucionalmente incrustadas e protegidas.

As profundas transformações tecnológicas e o intenso processo da chamada reestruturação produtiva redimensionaram os padrões da sociabilidade e reconfiguraram o mundo do trabalho. Dessa forma, o capital orientado na direção da ampliação crescente da acumulação evidencia o processo do binômio mundialização do capital/“globalização da pobreza" (Chossudovsky, 1999) como uma nova configuração do capitalismo, estruturando mecanismos que definem seu desempenho e formas de 
regulação social. Um importante aspecto da mundialização pode ser apontado: o processo de reorganização da produção e das relações entre capital e trabalho (Chesnais, 1996).

Apoiando-se na flexibilidade dos processos, frente à composição do mercado formal/informal do trabalho, bem como nos padrões de consumo, a mundialização caracteriza-se pela emergência de uma diversificada base de setores produtivos, "[...] novas maneiras de fornecimento de serviços financeiros, novos mercados e, sobretudo, taxas altamente intensificadas de inovação comercial, tecnológica e organizacional [...]" (Harvey, 2014, p. 140).

Esse processo se edifica e consagra diante da necessidade do capital em recuperar os longos períodos de exponenciais taxas de lucros, porém, a atualidade demonstra que o ritmo da organização capitalista migrou, rapidamente, dos processos de investimentos produtivos industriais, centrados na produção de bens de consumo, em mercadorias duráveis e não duráveis, para um enriquecimento exponencial, com destaque ao rentismo que, sustentado por uma "invisibilidade" que converte a especulação dos mercados, agora profundamente financeirizados, evidencia a prevalência do capital especulativo sobre o produtivo.

Muito embora a esfera financeira do capital contribua para seu processo de reprodução, é necessário compreender que ela se coloca de modo muito restrito, pois o capitalismo financeiro-especulativo segue nutrindo-se da riqueza auferida pelas esferas ampliadas de investimento do capital produtivo e esse processo se coloca a partir da apropriação da força de trabalho excedente. Redunda, assim, a partir da lógica do capital, como um processo pelo qual o capital-dinheiro emerja como sustentáculo de um poder de gerar mais dinheiro, ainda que no restrito das finanças. Reside aí o fetichismo dos mercados (Husson, 2009).

Mesmo diante de um largo processo de migração das ulteriores (e não superadas) formas de produção de bens de consumos duráveis para a esfera financeira, de caráter rentista, necessário destacar que não se remove a validade da apropriação da força de trabalho humana, uma 
vez que essa contradição é ineliminável das relações sociais, sendo que a exploração do trabalho vivo segue acentuada diante da utilização/ produtividade da força de trabalho (Chesnais, 2010).

À sombra da incontrolabilidade do capital, exponencialmente determinada por sua necessidade sociometabólica de expansão e de constante valorização, segue sua considerada lógica destrutiva, em que pese o aprofundamento da concorrência intercapitais, submetendo o valor de uso ao valor de troca, como modelo que impõe uma crescente necessidade de autorreprodução, ao passo que lança os despojos desse modelo socioeconômico ${ }^{2}$ para a genericidade humana.

A crise estrutural atual corresponde, diretamente, à incapacidade programada do próprio capital em resolver os problemas gerados no âmbito de seu metabolismo, em que a ausência de respostas à crise emerge, diretamente, como necessária para seu constante ciclo de (re)produção, ao passo que apenas gerencia a crise e os problemas que causam disfunções acumulativas (Sampaio Junior, 2011).

Embora as crises cíclicas do capital demonstrem suas contradições operantes, servem de "[...] alavancas para o aumento exponencial no poder aparentemente ilimitado de autopropulsão do capital [...]" (Mészáros, 2011a, p. 798), ainda que tais alavancas não cancelem as profundas assimetrias que compõem as esferas da produção e do consumo, bem como as determinações estruturais do capitalismo, mas acentuem suas contradições, assumindo, então, a presença de uma crise estrutural.

A chamada crise do capital não se opera apenas no processo de sua expansão, de sua necessidade constante de valorização, tendo em vista a extensa massa de força de trabalho disponível gerada no núcleo dessa crise de produção e sua complexa cadeia para atendimento das suas

2 Para Chesnais (2010), é necessário entender que o capital não pode ser concebido a partir de modelo centrado na esfera da sua reprodução, na esfera restrita da economia, apenas. Trata-se de um sistema que supera os limites da economia, dirigindo-se à dominação social, ideológica, a serviço de uma elite que, orientada à preservação, à ampliação e à hierarquização da riqueza, sustenta as condições de mantê-lo como tal. 
necessidades de reprodução, em que a divisão do trabalho emerge como agente que vai nutrir tal necessidade.

Lembremos a claríssima distinção entre divisão social do trabalho e divisão capitalista do trabalho desenvolvida por Lukács (2013), ao afirmar que a distinção destas reside na atividade-fim, sendo que para a primeira figura-se como uma atividade mediada entre o físico e espiritual, e a segunda, centrada na prevalência da quantidade (Infranca, 2014). Criaram-se, assim, na esfera do capital, "[...] as condições que possibilitaram tornar excedente e supérflua uma parcela considerável de trabalhadores" [...] (Lara; Maranhão, 2019, p. 57).

No contexto da crise que se avoluma, pelo achatamento da taxa de lucro, o capital requisita do Estado formas de intervenção para sua (re)produção, demonstrando, inconteste, que a partir da crise, “[...] todo discurso e a defesa da eficiência do mercado, da privatização, da desregulamentação se 'desmancham no ar' [...]”, assim, emerge o “[...] o fundo público para socializar os prejuízos” (Salvador, 2010, p. 50-51).

Nas crises agudas, cabe ao Estado intervir nas mais variadas esferas de reprodução do capital, em que ele envida os mais consistentes esforços político-econômicos a fim de sanear as dificuldades da produção. A propalada "mão invisível" smithiana, recuperada por economistas e apologetas (neo)liberais, é amputada com único e exclusivo objetivo de socorrer, com vultosos fundos públicos, as desastrosas aventuras do capitalismo, garantindo, assim, a regência do capitalismo expresso na lei do valor (Tavares, 2004).

\section{As relações Estado-sociedade no capitalismo: a falácia do terceiro setor}

Chamado a afirmar o agigantamento exponencial das taxas de lucro do capital, o Estado burguês ou, nos termos de Marx e Engels (1998, p. 12), este Estado moderno, que “[...] não passa de um comitê para gerenciar os 
assuntos comuns de toda a burguesia [...]", assume papel fundamental neste processo, pois sua função cartorial é legitimar os interesses do capital em torno de sua constante valorização, seja na produção, seja na esfera financeira, seja até mesmo nas políticas sociais, estas assentadas como "mercadorias" e/ou serviços destinados àqueles que podem pagar. É nessa esfera de poder político profundamente mediado com o poder econômico que o Estado desempenha uma gama de funções (Netto, 2005).

A busca de uma suposta saída da crise vai encontrar lastro na organização estatal ao possibilitar ao capital sua manifestação nas mais diversas áreas da vida social, seja na economia, seja no trabalho, seja nas políticas sociais, redesenhando profundamente as configurações das relações Estado-sociedade.

É necessária a compreensão do princípio de uma simbiótica subsidiariedade entre as esferas pública e privada, sendo, na atualidade, profundamente estimulada sua desresponsabilização, por parte do Estado, de diversos deveres. Atribui-se, em sua substituição, a responsabilização à família, ao cidadão e à comunidade, ficando reservadas ao Estado as colaborações em forma de subvenções às organizações sociais e a execução de determinadas ações diretas, apenas de natureza emergencial.

Conta-se com uma forma de financiamento das ações privadas, sistematicamente realizadas pelo fundo público por meio de convênios ou, indiretamente, por renúncia fiscal, subvenções e cessão de bens, direitos e valores. $\mathrm{O}$ fato de os serviços prestados não serem pagos faz com que sejam associados à concepção de que são dirigidos às pessoas incapacitadas de pagar, o que tem levado à necessária demonstração de pobreza e à consequente comprovação do estado de miserabilidade para ser incluídas, ou seja, para ter acesso a bens e/ou serviços, a comprovação (vexatória, por sinal) da pobreza antecede e se torna baliza frente às básicas necessidades da (re)produção humana.

Não se constata uma preocupação em identificar necessidades e analisar as demandas com o estabelecimento de propostas e a definição dos padrões de atendimento dessas demandas como política pública, 
havendo apenas atendimento pontual de alguns "necessitados" ou de algumas "necessidades". Tal forma de inclusão, mediante a comprovação das necessidades, não reflete o direito social deste sujeito, mas, pela chamada cidadania invertida, pela comprovação de uma não cidadania, que, segundo Fleury (1994, p. 44), figura-se no momento em que

[...] Nesta condição política de cidadania invertida, o indivíduo entra em relação com o Estado no momento em que se reconhece como um não cidadão. Os seus atributos jurídicos e institucionais são, respectivamente, a ausência de uma relação formalizada de direito ao benefício, o que reflete na instabilidade das políticas sociais nesta área, e uma base institucional inspirada em um modelo de voluntariado das organizações de caridade, mesmo quando são instituições estatais.

A forma vexatória de demonstração de incapacidade de pagar ou comprar transforma a atenção prestada em um processo de ajuda precária, fragmentada, focalizada, emergencial e desvinculada de garantia da qualidade ou do acesso universal às políticas sociais setoriais. Para Pereira (2000, p. 29, grifo do original), “[...] deve-se estruturar e se organizar em torno do eixo das necessidades humanas, geradas por desigualdades de ordem social e econômica, e não em torno de um padrão de clientela produzida perversamente, que nem deveria existir". Para qualificar o tipo de política pública a ser adotada e que requer ser amplamente defendida, Pierson (2006, p. 11) cita importantes identificações necessárias que precisam ser compreendidas, tais como:

a) identificação dos princípios que fundamentam a política: seletividade ou universalidade; b) identificação do tipo de pobreza a ser enfrentada pela política: absoluta (baseada simplesmente no critério da renda), ou relativa (baseada na renda e em outros indicadores de desigualdade social), ou ambas; c) identificação do caráter da distribuição de bens e serviços sociais: regressivo ou progressivo; d) identificação do nível e da qualidade do atendimento oferecido: mínimo, acima do mínimo ou ótimo; e) identificação dos impactos da política na estrutura da oferta: dualização ou 
nivelação; f) identificação da natureza da oferta da política: estigma ou melhoria do "status" do cidadão; g) identificação dos mecanismos de controle, na oferta da política: comprovação constrangedora de pobreza ou não; h) identificação do tipo de pluralismo embutido nas propostas de parceria na realização da política: residual ou institucional.

Tais identificações suscitam uma necessária reflexão sobre a dimensão que a política pública precisa ocupar no terreno das satisfações das necessidades humanas, ao passo que, para o capital, sua relação torna-se inversa. Nesse sentido, transita, dentro e fora dos limites do Estado, uma belicosa relação de apropriação da política pública pelo terceiro setor e que, pela natureza empresarial que lhe é característica, transmuta os critérios de inclusão em critérios de seleção (excludentes), sustentando-os como serviços, descolando mais ainda a responsabilidade do Estado na sua formulação, implementação, execução, monitoramento e avaliação.

Nesse cenário, a dissociação do Estado da ordem burguesa torna-se cada vez mais difícil, pois se figura a partir da dualidade de um projeto que introduziu tal ordem e que serve de medida e espaço para a reprodução do controle político-econômico daqueles que detêm o monopólio dos meios de produção. Assim, é necessário entender que as profundas relações capital-Estado solidificaram uma relação de dependência, em que prevalecem os determinantes do capitalismo e ao Estado cabe o papel de legalizar suas ações, evidenciando que: "O Estado, o regime político, é o elemento subordinado; e a sociedade civil, o reino das relações econômicas, é o elemento dominante" (Engels, 1975, p. 111).

O Estado emerge como um Estado da Coerção e do Consenso, aumentando progressivamente a participação popular e, consequentemente, a cidadania, incorporado pelos setores dominantes que procuram impedir os avanços populares. A democracia, a participação e a cidadania são utilizadas tanto para legitimar o poder, a dominação e o status quo, quanto para lutar contra eles e contra as desigualdades sociais operantes (Gorender, 1988). 
A legitimação ocorre, por um lado, com a ampliação dos direitos trabalhistas e das políticas sociais e, por outro, pela ampliação da cidadania, conformando a legitimação na perpetuação e no desenvolvimento da lógica capitalista pelo Estado, incorporando a lógica democrática e implicando sua constante ampliação, tanto em termos quantitativos, como qualitativos.

Tal contradição não se estabelece entre o capitalismo e o Estado, mas entre o capitalismo e as plenas cidadanias e as democracias substantivas, como afirmou Coutinho (1999). Para resolver este dilema, transfere-se a questão da legitimação da ordem, deslocando-se das "lógicas do Estado" para as "lógicas da sociedade civil", reforçando o discurso operante de autossatisfação das necessidades básicas do ser social, ou seja, traduz-se pela lógica de uma individualização da questão social ou mesmo centrada em um voluntarismo "civil", que não demonstra, de modo fático, uma solidariedade de classe.

O Estado assume a solução do problema e da responsabilidade, legitimando a solução dos dilemas cruciais da ordem capitalista, além de socializar seus custos, o que provoca o risco de inviabilizar o próprio sistema que ajuda a perpetrar. Convive-se com uma nova estratégia de legitimação do capitalismo, completamente inversa, que resulta numa série de ações concretas e diretas nos Estados neoliberais, sendo estabelecida como eixo central à passagem das lógicas do Estado para as lógicas da sociedade civil, ou para as lógicas do mercado.

Entende-se que, na sociedade civil, o fundamento é qualitativo, não fazendo referência a quem constitui maioria, mas significando apenas aqueles que são detentores de maior poder político e econômico - o poder de decisão. A chamada passagem das "lógicas do Estado" para as "lógicas da sociedade civil" constitui-se, a partir de então, em uma ampliada "esfera de todas as virtudes" (Pfeifer; Simionatto, 2006, p. 2).

O aparelho estatal é impelido a não mais corresponder às suas funções, o que possibilita entender os fundamentos político-econômicos das privatizações, do redirecionamento do fundo público, das profundas 
retrações nos direitos sociais, as reformas constitucionais e, nesta clivagem, a expansão do "terceiro setor".

Esse terceiro setor funda-se com base nos seguintes aspectos: possibilita a passagem das questões econômicas de forma despolitizada do Estado para a sociedade civil ou, em outras palavras, para o mercado. Promove a manutenção no próprio Estado de algumas áreas sociais de maneira despolitizada e deseconomizada de seus processos formais, o que leva, invariavelmente, à imposição de um conteúdo supostamente de problemas de cunho psicossociais, ocultando a verdadeira raiz centrada na confrontação entre capital e trabalho.

Tal situação resulta na conversão do estatal em público e do mercado econômico em privado, promovendo-se uma dicotomia entre Estado e sociedade civil, como campos autônomos. Além do Estado e do mercado, há o "terceiro setor", não governamental e classificado como não lucrativo, sustentado por uma proposta de tratar a questão social, contribui para a precarização, remercantilização e refilantropização, significando a coexistência de uma política pública estatal profundamente precarizada. Isso repõe um tipo de política marginalizada, focalizada e desconcentrada, evidenciando um tipo de resposta do Estado à questão social que, destinada àqueles considerados mais necessitados, reforça seu caráter setorializado e minimalista (Silva; Souza, 2019).

Nesta configuração, a chamada filantropia assume a condução das políticas públicas, em uma pretensa substituição ao Estado, ofertando "acesso" às camadas empobrecidas da classe trabalhadora que não conseguem acessar a política social estatal, contrapondo-se como alternativa centrada numa reatualização conservadora de uma política sustentada por princípios voluntaristas, assistencialistas, muitas vezes de caráter religioso, em que impera um conceito de mutualidade, ou, como querem seus apologetas, de ajuda mútua (aclassista, evidentemente).

Com a expansão do "terceiro setor", segundo alguns experts, a sociedade civil será reforçada, e, ainda, com a redução do poder do Estado, cria-se um espaço alternativo de produção/consumo de bens e serviços, 
não mercantilizados e estimulados pelos laços de solidariedade local, para o "tratamento" das refrações da questão social.

Não conhecemos propostas de superação do capitalismo no rol de propostas do terceiro setor, não podendo, então, ser caracterizado como alternativo ao sistema, mas sim funcional ao próprio sistema. A justificativa de mérito para o terceiro setor seria a sua desvinculação do lucro - algo que o Estado nunca objetivou —, restando, apenas, a distinção entre o Estado e terceiro setor como governamental e não governamental.

Quando o Estado não responde às necessidades sociais, podem-se afirmar laços de solidariedade local, particularizada em oposição à chamada solidariedade universal, coletiva, de classe. Acarreta, ainda, o aprofundamento da particularização e da fragmentação, reforçando a solidariedade com seus pares, privilegiando interesses particulares em detrimento dos interesses coletivos, atribuindo a cada segmento particular as respostas para suas próprias demandas.

Por se estabelecerem em microespaços, as políticas sociais promovidas pelo terceiro setor são fragmentadas e de reduzida abrangência, sendo impossível e inviável que venham a substituir o Estado, principalmente nos aspectos de quantidade, variedade e qualidade, estruturando-se a partir de uma lógica fragmentadora.

O terceiro setor promove a refilantropização dos espaços socioinstitucionais devido à possibilidade de substituição das ações em políticas públicas por ações filantrópicas, alterando os princípios que deram sustentação durante este século às relações sociais, atingindo três objetivos neoliberais: a mercantilização dos bens sociais, a conversão ideológica do investimento social público em gasto social e sua consequente redução, e a supressão da noção e dos direitos sociais (Laurell, 2008).

Concordamos que deve haver progressiva e ativa participação da sociedade civil, porém, não podemos concordar que isso redunde na simples substituição da responsabilidade estatal e, por consequência, do próprio capital com a questão social, nem que sejam abandonados os princípios de universalização, distributivismo e incondicionalidade 
como características de políticas sociais públicas, de cidadania efetiva, afiançadoras e consagradoras das lutas históricas da classe trabalhadora (Rodrigues, 2002).

\section{Algumas considerações finais}

A contemporaneidade recebeu a herança produzida no século XX, em que o desemprego estrutural se globalizou, como o capital, mas os lucros são apropriados por grandes corporações que se nutrem da superexploração globalizada, realizada nos longínquos rincões, cujo critério de escolha pelo capital é o de buscar força de trabalho com menor preço, associado à isenção de impostos e demais facilidades fiscais para que a mais-valia seja potencializada e, por consequência, produzindo altas de taxas de lucratividade.

Evidencia-se grande capacidade em concorrer nos mercados e, por outro lado, o desemprego, a miséria, a exclusão social e a fome, apesar de concretamente globalizados, devem ser solucionados por Estados nacionais, individualmente, ou pior, os custos sociais recaem diretamente sobre os trabalhadores, diante de uma frágil intervenção estatal.

O discurso da competitividade clama pelo enxugamento do Estado, o fim das barreiras alfandegárias, pela não interferência estatal nos mercados, impondo, por meio dos organismos internacionais, o fim do déficit público, a especialização do Estado com a definição de sua atividade-fim: segurança, a proteção dos improdutivos (pessoas com deficiências, idosos e crianças). Os outros - adultos e adolescentes em idade produtiva - deverão ser sujeitos de ações assistenciais privadas, ou seja, da sociedade, que deveria assumir os seus custos pelo voluntariado, pelas contribuições das pessoas etc.

De fato, esta foi a máscara que cobriu a verdadeira realidade: a socialização do custo da reprodução social da classe trabalhadora, que passou a ser coberto pelos próprios trabalhadores, mas que desoneraram o Estado e não foram assumidos pelo capital. 
Também emerge a falácia do terceiro setor ao lucrativo, como já vimos, que privatiza ações do Estado sob o manto de uma sociedade civil, mas subvencionado com o dinheiro público, atua no ramo da filantropia, termo utilizado para identificar grande parcela do chamado terceiro setor ou "sociedade civil" (conceito muito mal empregado), que possibilita acumular vantagens pessoais, apropriação de recursos públicos para interesses privados, acentuando seu conteúdo econômico e ideológico.

Tal desresponsabilização estatal causa uma redução dos princípios consagrados na Constituição Federal de 1988, que indicou a exigência da institucionalização de cidadania como dever do Estado e direito do cidadão. A questão acabou por implantar um desmonte dos direitos, pois, na relação com o Estado, é possível ser cidadão, visto que o Estado, detentor do dever de responder pela demanda dos direitos, pode ser compelido a cumprir sua responsabilidade pela esfera judicial do próprio Estado.

A esfera privada, mais especificamente o terceiro setor, não responde pela obrigação de fazer como o Estado. Faz o que deseja, quando decide, não se tratando de ação definitiva ou duradoura, tem apenas o papel de gestão dos recursos públicos destinados ao desenvolvimento de seus programas, serviços e/ou projetos.

Disso se pode concluir que os recursos públicos são mais eficazes sob gestão pública, pois respondem aos direitos dos cidadãos e não aos favores, uma vez que o terceiro setor realiza ações fragmentadas, pontuais, discriminatórias, e mais grave ainda, realizadas em grande parte de forma confessional, muito embora o Estado brasileiro seja laico e não seja permitido o repasse de recursos públicos para denominações religiosas.

Entretanto, tais instituições acabam utilizando o instituto de criar sociedades civis, em que seus estatutos afirmam o seu caráter aconfessional, mas são administradas por dirigentes de grupos religiosos e, em sua maioria, utilizam critérios parciais que acabam beneficiando seus seguidores, fornecendo benefícios, serviços e programas e, com isso, fidelizando uma privada e flagrante clientela. 
Tal maneira de pensar a cidadania parece instalar o que se poderia chamar de cidadania bancária, que poderá ser entendida como uma determinação de o cidadão cumprir suas obrigações e depositá-las no "Banco da Cidadania", e, quando tiver saldo, poderá sacar seus direitos, ou seja, um conceito de contraprestação. Com relação aos deveres, todo cidadão tem deveres que são exigíveis em relação aos direitos de cidadania dos outros cidadãos, ou seja, para que possam existir os direitos coletivos de cidadania.

Atualmente, em razão da crise de produção em escala global, com severos desdobramentos nos países de economia dependente, e por requisição do mesmo capital globalizado, nos últimos 50 anos, o capitalismo expandiu seus lucros, acumulou como jamais se viu, apropriou-se individualmente da riqueza produzida e, diante do seu dilema endógeno, o capital procura soluções e saídas mágicas, tal qual a mitológica Ariadne, filha de Minos de Creta.

Sabemos que não há saídas mágicas, pois o capital segue pleiteando e aprofundando sua riqueza, uma vez que tributa aos trabalhadores a socialização dos seus prejuízos, sendo nada mais que o resultado de seu processo de acumulação predatório e autofágico. Sua suplantação é condição sine qua non para superar o dilema deste profundo declínio civilizatório que conduziu a humanidade à barbárie.

\section{Referências}

ALVES, G. O declínio civilizatório do capital. In: SILVA, L; SOUSA, E. A. (org.). Trabalho, questão social e Serviço Social: a autofagia do capital. São Paulo: Cortez, 2019.

ANTUNES, R. Adeus ao trabalho? Ensaios sobre as metamorfoses e a centralidade do mundo do trabalho. 8. ed. São Paulo: Cortez; Campinas: Editora da Unicamp, 2003.

BEHRING, E. R. O Brasil e a mundialização do capital: privatização, deslocalização e flexibilização das relações de trabalho. In: SERRA, Rose (org.). Trabalho e reprodução: enfoques e abordagens. São Paulo: Cortez; Rio de Janeiro: PETRES-FSS/UERJ, 2001.

COUTINHO, C. N. Democracia e modernidade. Perspectivas, São Paulo, n. 22, 1999. 
CHESNAIS, F. A mundialização do capital. São Paulo: Xamã, 1996.

CHESNAIS, F. Crisis de sobreacumulación mundial, crisis de civilización. Buenos Aires: Herramienta, 2010.

CHOSSUDOVSKY, M. A globalização da pobreza: impactos das reformas do FMI e do Banco Mundial. São Paulo: Moderna, 1999.

ENGELS, F. Ludwig Feuerbach e o fim da filosofia clássica alemã. In: MARX, Karl; ENGELS, Friedrich. Textos. São Paulo: Edições Sociais, 1975. (Primeira edição alemã, 1888.)

FLEURY, S. M. Estado sem cidadãos. São Paulo: Editora Fiocruz, 1994.

GORENDER, J. Coerção e consenso na política. Estudos Avançados, São Paulo, v. 2, n. 3, 1988.

HARVEY, D. Para entender o capital. São Paulo: Boitempo, 2014. Livros I e II.

HUSSON, M. Finanzas, hipercompetencia y reproducción del capital. In: BRUNHOFF, S. de et al. Las finanzas capitalistas: para comprender la crisis mundial. Buenos Aires: Herramienta, 2009.

INFRANCA, A. Trabalho, indivíduo e história: o conceito de trabalho em Lukács. São Paulo: Boitempo, 2014.

LARA, R; MARANHÃO, C. Fundamentos do trabalho e "questão social" e serviço social. In: SILVA, M. L. O.; SOUZA, E. A. S. (org.). Trabalho, questão social e Serviço Social. São Paulo: Cortez, 2019.

LAURELL, A. C. Avançando em direção ao passado: a política social do neoliberalismo. In: LAURELL, Asa Cristina (org.). Estado e políticas sociais no neoliberalismo. 4. ed. São Paulo: Cortez, 2008.

LUKÁCS, G. Para uma ontologia do ser social II. São Paulo: Boitempo, 2013.

MANDEL, E. O capitalismo tardio. São Paulo: Abril Cultural, 1985.

MARX, K.; ENGELS, F. O manifesto do partido comunista. São Paulo: Cortez, 1998.

MÉSZÁROS, I. Para além do capital: rumo a uma teoria da transição. Tradução: Paulo Cezar Castanheira e Sérgio Lessa. São Paulo: Boitempo, 2011a.

MÉSZÁROS, I. Estrutura social e formas de consciência: a determinação social do método. São Paulo: Boitempo, 2011b.

NETTO, J. P. Capitalismo monopolista e Serviço Social. 2. ed. São Paulo: Cortez, 2005.

PEREIRA, P. A. P de. Necessidades humanas: subsídios à crítica dos mínimos sociais. São Paulo: Cortez, 2000. 
PFEIFER, M.; SIMIONATTO, I. Responsabilidade social das empresas: a contraface da sociedade civil e da cidadania. Textos \& Contextos, Porto Alegre, n. 5, 2006.

PIERSON, C. Beyond the Welfare State? The new political economy of welfare. Cambridge: Polity Press, 2006.

RODRIGUES, J. A. Serviço Social e assistência social: cidadania e projeto ético-político profissional. 2002. Dissertação (Mestrado) - Universidade Estadual Paulista, Franca, 2002.

SALVADOR, E. Crise do capital e o socorro do fundo public. In: BOSCHETTI, I. S. et al. Capitalismo em crise: política social e direitos. São Paulo: Cortez, 2010.

SAMPAIO JUNIOR, P. A. A crise estrutural do capital e os desafios da revolução. In: JINKINGS, Ivana; NOBILE Rodrigo (org.). Mészáros e os desafios do tempo histórico. São Paulo: Boitempo, 2011. p. 199-210.

SILVA, M. L. O; SOUZA, E. A. Cipoal da insegurança: capitalismo flexível, neoliberalismo e as condições de trabalho de assistentes sociais que atuam na Seguridade Social no Brasil. In: SILVA, M. L. O; SOUZA, E. A. S (org.). Trabalho, questão social e Serviço Social. São Paulo: Cortez, 2019.

TAVARES, M. A. Os fios (in)visíveis da produção capitalista: informalidade e precarização do trabalho. São Paulo: Cortez, 2004.

\section{Sobre o autor}

Reginaldo Pereira França Junior - Doutor em Serviço Social. Professor adjunto II do curso de Serviço Social.

E-mail: Reginaldo.pereira@professor.ufcg.edu.br. 